\title{
Article
}

\section{The Effects of the Pilates Method on Pelvic Floor Injuries during Pregnancy and Childbirth: A Quasi-Experimental Study}

\author{
Carmen Feria-Ramírez ${ }^{1}$, Juan D. Gonzalez-Sanz ${ }^{1,2, * \mathbb{D}}$, Rafael Molina-Luque ${ }^{3,4} \mathbb{( D}$ and Guillermo Molina-Recio ${ }^{3,4}(\mathbb{D}$ \\ 1 Departamento de Enfermería, Universidad de Huelva, 21071 Huelva, Spain; carmen.feria@denf.uhu.es \\ 2 Centro de Investigación en Pensamiento Contemporáneo e Innovación para el Desarrollo Social (COIDESO), \\ Universidad de Huelva, 21071 Huelva, Spain \\ 3 Grupo Asociado de Investigación Estilos de Vida, Innovación y Salud, Instituto Maimónides de Investigación \\ Biomédica de Córdoba (IMIBIC), 14004 Córdoba, Spain; Rafael.moluq@gmail.com (R.M.-L.); \\ en1moreg@uco.es (G.M.-R.) \\ 4 Departamento de Enfermería, Farmacología y Fisioterapia, Facultad de Medicina y Enfermería, \\ Universidad de Córdoba, 14041 Córdoba, Spain \\ * Correspondence: juan.gonzalez@denf.uhu.es
}

check for updates

Citation: Feria-Ramírez, C.; Gonzalez-Sanz, J.D.; Molina-Luque, R.; Molina-Recio, G. The Effects of the Pilates Method on Pelvic Floor Injuries during Pregnancy and Childbirth: A Quasi-Experimental Study. Int. J. Environ. Res. Public Health 2021, 18, 6995. https:// doi.org/10.3390/ijerph18136995

Academic Editors: Anna Polak,

Bogdan Bacik, Agnieszka

Nawrat-Szoltysik and Maria Grazia Porpora

Received: 14 May 2021

Accepted: 24 June 2021

Published: 30 June 2021

Publisher's Note: MDPI stays neutral with regard to jurisdictional claims in published maps and institutional affiliations.

Copyright: (c) 2021 by the authors. Licensee MDPI, Basel, Switzerland. This article is an open access article distributed under the terms and conditions of the Creative Commons Attribution (CC BY) license (https:// creativecommons.org/licenses/by/ $4.0 /)$.

\begin{abstract}
The perineal injuries suffered during childbirth have a great impact on the quality of life of the female population. Evidence suggests that the Pilates method is used by pregnant women to improve the physical and psychological outcomes of pregnancy. The aim of this study was to investigate the influence of the Pilates Method during pregnancy on the incidence and degree of intrapartum perineal trauma. A quasi-experimental study was carried out between November 2018 and December 2019 at different health centers in two health districts. Participants were 72 pregnant women attending the antenatal program, who were assigned to a Pilates group or a control group (48 and 24 pregnant women, respectively). The main outcome measurement was perineal trauma during childbirth. After participating in the Pilates program, the women in the experimental group were significantly less likely to suffer perineal trauma in spontaneous deliveries compared to the women in the control group. After evaluating these results, it is concluded that health center managers should promote the training of midwives in the prevention and treatment of pelvic floor injuries during pregnancy and should consider strategies to enhance adhesion and participation with respect to pelvic floor exercise programs throughout pregnancy by means of Apps and other digital media specifically aimed at this phase.
\end{abstract}

Keywords: nursing; midwifery; nurse; Pilates method; pelvic floor; injuries; episiotomy

\section{Introduction}

It is well known that female pelvic floor $(\mathrm{PF})$ weakness and/or pelvic floor dysfunction (PFD) can have both structural and functional effects, such as urinary incontinence, bowel incontinence, pelvic organ prolapse, and dyspareunia and/or sexual dysfunction [1-4]. One of the main risk factors associated with pelvic dysfunction is the reproductive process, including pregnancy and birth. During this process, both modifiable and nonmodifiable risk factors for PFD can be identified. Chief among the former are the pregestational and full-term body mass index (BMI), weight gain, smoking, the type of birth, the use of forceps, the duration of the first and second stages of birth, the practice of episiotomy, and the use of epidural anesthesia. Among the nonmodifiable risk factors (also known as risk indicators) are age at maternity, position of the fetus and circumference of the newborn's head, the weight of the newborn, and the presence/existence of perineal injury, chiefly those which can affect the anal sphincter $[1,3]$.

Of all these factors, vaginal birth is the chief modifiable risk factor for developing PFD, as women in this group are 2.8 times more likely to suffer stress urinary incontinence, and 5.5 times more likely to suffer a prolapse of the pelvic organs, in comparison to those who 
give birth via caesarean section. These risks increase with instrumental delivery, which seems to be related to the fact that the incidence of injury to the anal musculature is higher in this procedure [5].

Among the nonmodifiable obstetric risk factors, chief is perineal trauma, whether spontaneous or induced (second-degree tears or obstetric anal sphincter injuries), which represents one of the most frequent complications associated with birth $(85 \%$ of puerperal women) and has a clear influence in the subsequent appearance of PFD [6,7].

Although in recent years the practice of routine episiotomies has decreased in Spain, the percentage remains above the recommendations of the WHO at around $40.2 \%[6,8,9]$.

Perineal wounds suffered during birth significantly increase the risk of PFD, with a consequent impact on the quality of life of female population $[1-3,10]$.

Primary prevention of PFD is therefore essential, and the following interventions have been shown to be effective: (1) perineal massage during pregnancy [11], (2) weight management and the promotion of physical exercise [12,13], and (3) PF strengthening exercises, which help to reduce discomfort and reduce the risk of urinary incontinence in the third trimester of the pregnancy and after childbirth $[3,6]$.

With respect to exercises for strengthening the $\mathrm{PF}$, the most common are hypopressive abdominal exercises and the Pilates Method (PM), which focus on developing the musculature of the transverse abdominis and pelvis in order to decrease intra-abdominal pressure [13].

Pilates is based on control, strength, and flexibility. It focuses particularly on the abdominal muscles, vertebral column, and PF, and is thus instrumental in improving body alignment and good posture [14-17]. Advocates also note that practitioners gain a greater personal health, among other benefits [18,19].

Given the marked increase in practicing Pilates during pregnancy, various studies have been carried out to evaluate its effectiveness $[14,16,20]$. With regard to the specific relation of Pilates with PFD, two studies found a positive impact on the PF musculature during pregnancy [21,22], while another study concluded that the method was a valid means of helping to prevent the dysfunction [23].

The starting hypothesis of this study was that the incidence of perineal wounds during childbirth would be lower among those participating in a specially designed Pilates program. Therefore, the aim of this study was to evaluate the influence of Pilates sessions during pregnancy on the incidence and degree of intrapartum perineal injuries.

\section{Materials and Methods}

\subsection{Study Design}

This study was a 4-week multicenter quasi-experimental trial conducted from November 2018 through December 2019. Pregnant women who received routine antenatal care in health centers (HCs) pertaining to two distinct health districts were eligible to enroll.

\subsection{Sample/Participants}

All pregnant women who were attending antenatal classes at HCs in two distinct districts were informed by the midwife of the possibility of taking part in the study if they met the inclusion criteria. The inclusion criteria were as follows: (1) being registered on an antenatal program (AP), (2) giving written consent of participation, (3) the pregnancy being a singleton, (4) the pregnancy being low risk [24], (5) there not being any contraindications for physical exercise, and (6) being at least 18 years old.

Women who had missed antenatal appointments, had difficulty in speaking or understanding Spanish, had given birth by caesarean section, or declined to participate were excluded from the study.

\subsubsection{Interventions}

The study was carried out in two stages: the first involved finding Pilates trainers to deliver the sessions, while the second collated participant data from both the experimental 
and control groups. The first phase took place in November 2018, with the collaboration of two trainers in Huelva and one in Seville, all with the same training background. The second phase was carried out between December 2018 and December 2019 in the corresponding HCs in Huelva and Seville.

In order to eliminate potential bias as a result of the antenatal classes being delivered by health professionals of different categories, only those HCs where classes were delivered by a midwife were selected for the study. The women participating in the corresponding antenatal classes at the respective centers were then invited to participate in the study, and assigned either to the experimental group $(\mathrm{AC}+\mathrm{PM})$ or to the control group ( $\mathrm{AC}$ only).

\subsubsection{Experimental Group}

The women in the experimental group received two one-hour Pilates sessions per week over a period of 4 weeks (Appendix A. In addition, the participants received their usual antenatal classes at their respective HCs in accordance with the Comprehensive Healthcare Program for Pregnancy, Childbirth, and Postpartum (CHPPCP) from the Andalusian Regional Government [24].

\subsubsection{Control Group}

The women in the control group received solely the antenatal classes at their corresponding centers as programmed (Table 1).

Table 1. Schedule of sessions of the Maternal Education Program of the health service received by pregnant women participants.

\begin{tabular}{|c|c|}
\hline Class Number & Theme of the Session \\
\hline $\begin{array}{c}\text { Session } 1 \\
\text { (Initial measurement) }\end{array}$ & Physiological changes during pregnancy \\
\hline Session 2 & Childbirth \\
\hline $\begin{array}{c}\text { Session } 3 \\
\text { (Intermediate measurement) }\end{array}$ & Care of the newborn \\
\hline Session 4 & The postpartum period \\
\hline $\begin{array}{c}\text { Session } 5 \\
\text { (Final measurement) }\end{array}$ & Breastfeeding \\
\hline
\end{tabular}

\subsubsection{Sample Size}

A minimum sample size of 36 women was originally projected, for a confidence level of $95 \%$ and a power of $80 \%$, considering $49 \%$ avoiding episiotomy in the control group in comparison with $98 \%$ in the experimental group [25], and divided according to a ratio of 2 women in the control group for every woman in the experimental group. This number was increased in case any women dropped out, such that the final number of participants was 72, of which 24 pregnant women formed the experimental group and 48 pregnant women the control.

\subsection{Data Collection}

\subsubsection{Outcomes}

The outcomes variables were age (years), blood pressure $(\mathrm{mmHg})$, weight $(\mathrm{kg}), \mathrm{BMI}$ $\left(\mathrm{kg} / \mathrm{m}^{2}\right)$, starting level of physical activity, and tobacco use. These variables were all measured by experienced personnel at the start of the experimental phase, at two weeks, and again at four weeks after the treatment for both groups had been completed.

Variables relating to childbirth, birthweight $(\mathrm{kg})$, and weight gain during gestation were measured between the eighth and tenth day after birth by telephone interview and review of hospital medical history. To calculate the weight gain $(\mathrm{kg})$, the weight measured in the first trimester and the weight prior to delivery were taken as reference. The numbers 
of weeks of pregnancy at birth were measured on a discrete quantitative scale. Labor onset (spontaneous, stimulated, or induced), type of delivery (spontaneous, assisted delivery with forceps, Thierry's spatulas or vacuum extraction, or caesarean section), the use of intrapartum pharmacological analgesia (none, epidural anesthesia, sedatives, or nitrous oxide), and type of episiotomy (not required, median, lateral, or medio-lateral) were measured by nominal scales, while the degree of perineal tear was evaluated on an ordinal scale (no injury; first degree: laceration of the vaginal epithelium or perineal skin only; second degree: involvement of the perineal muscles but not the anal sphincter; third degree: disruption of the anal sphincter muscles, which is further subdivided into grade 3a: less than $50 \%$ thickness of external anal sphincter torn, grade $3 \mathrm{~b}$ : more than $50 \%$ thickness of external anal sphincter torn, and grade 3 c: internal anal sphincter also torn; fourth degree: a third-degree tear with disruption of the anal epithelium).

Weight $(\mathrm{kg})$ and height $(\mathrm{cm})$ were recorded during the routine antenatal appointments at the HCs using stadiometers with weight scale function. The level of physical activity was measured using the International Physical Activity Questionnaire (IPAQ) [26].

\subsubsection{Validity and reliability/Rigor}

The TREND recommendations were followed in the design and development of this research. To avoid bias in the assessment of the results, the professionals who assessed the progress of labor in the delivery room and completed the medical history did not know whether the woman belonged to the intervention or the control group.

\subsubsection{Ethical Considerations}

The study was carried out in keeping with the principles enshrined in the Declaration of Helsinki (1964), the Convention for the Protection of Human Rights and Dignity of the Human Being with regard to the Application of Biology and Medicine (1997), and the Universal Declaration on the Human Genome and Human Rights (1997), and also complied with the requirements stipulated by Spanish Law 3/2018 of the 5 December in the area of biomedical research, data protection, and bioethics. Approval from the bioethics committee of the Andalusia Health Service (SAS) was also obtained. Only data for which informed consent had been given in writing were used.

\subsubsection{Data Analysis}

The quantitative variables are presented with the mean and standard deviation, while the qualitative data are given in frequencies and percentages.

In order to measure the goodness of fit of the quantitative data to a normal distribution, a Lilliefors-corrected Kolmogorov-Smirnov test was used. Bivariate analysis was carried out with Student's $t$-test for the comparison of two means. In the case of the qualitative data, the chi-square test was used, except when Fisher's exact test was required. Likewise, for the analysis of three or more means, a repeated-measures ANOVA was used to evaluate the effects of the treatment in the two groups, at baseline and at three and five weeks. Correlation between the quantitative variables was verified using the Pearson coefficient correlation $(r)$. Finally, in order to allow for the possibility that the data did not meet the criterion of normality or homoscedasticity, nonparametric versions of the tests above were also carried out.

Binary logistic regression models adjusted for various qualitative and quantitative predictive variables were calculated in order to determine association of the variables with perineal trauma in childbirth.

The odds ratios (ORs) were determined with a confidence interval of $95 \%$. The goodness-of-fit tests (-2 log likelihood, goodness-of-fit statistic, Cox and Snell $R^{2}$, Nagelkerke $R^{2}$, and Hosmer-Lemeshow) were calculated to evaluate the overall fit of the model.

In all statistical analyses, alpha was set to below $5 \%$ or the significance level was established at $5 \%(p<0.05)$ and a confidence interval of $95 \%$ was computed. All statistical calculations were made using IBM SPSS Statistics version 25.0. 


\section{Results}

Over the period in which the study took place, 294 women attended the AC sessions in the participating health centers. After inviting those who met the selection criteria to participate, 47 women were chosen to form part of the experimental group and 75 women the control. Nine women from the experimental group were forced to drop out for reasons of family problems, contractions, or maternal illness, while six dropped out from the control group because of family problems, clashes with the schedule, and giving birth. It should also be noted that all participants who ultimately had a caesarean section (21 women in the control group and 14 women in the experimental) were excluded from the data. The final numbers of participants were 24 in the experimental group and 48 in the control. A flow chart of the participants at each stage of the study can be seen in Figure 1.

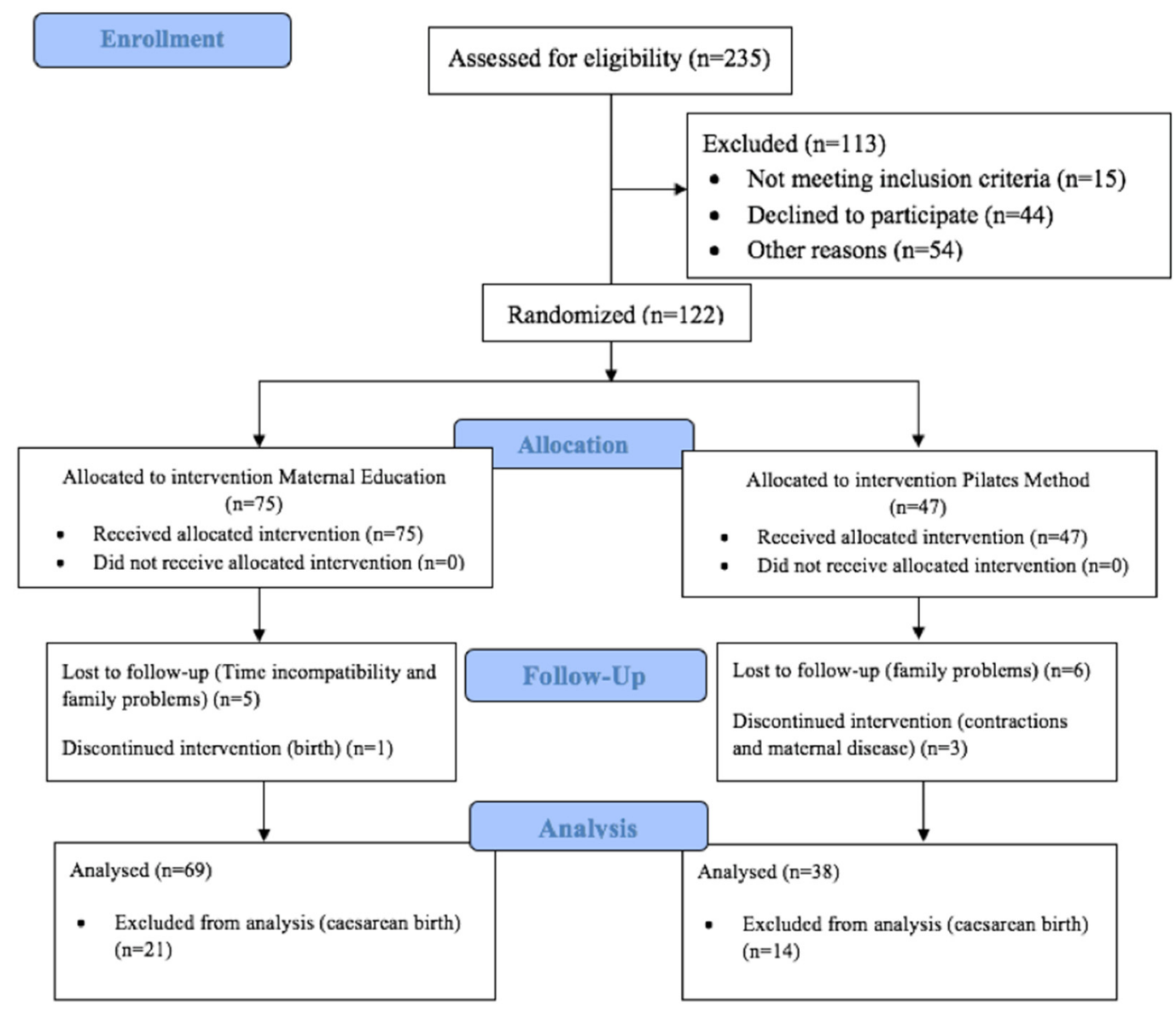

Figure 1. The flow diagram of the participants through each stage of the study.

\subsection{Characteristics of the Sample}

Of the 72 women who finally participated in the study, 24 attended the PM sessions (experimental group), while 48 attended solely the usual AC (control group). The average age of participants at the start of the study was 32.4 (5.2) years old; body mass index was 25.2 (3.8), indicative of slight overweight; systolic and diastolic blood pressure values were 110.8 (10.5) and $67.6(8.5)$, respectively, and lifestyle habits involved low physical activity $(45.8 \%)$ and generally no tobacco use $(94.4 \%)$. With respect to the gestational age at the point of recruitment to the study, the average of all participants was 27.3 (3.7) weeks. For none of these variables were significant differences found between the women in the experimental group and those in the control group. More detailed information on the baseline condition of both groups can be found in Table 2 . 
Table 2. Demographic characteristics of 72 pregnant women who received prenatal care ${ }^{1}$.

\begin{tabular}{|c|c|c|c|c|}
\hline Variable & $\begin{array}{c}\text { Total } \\
(n=72)\end{array}$ & $\begin{array}{l}\text { Assistance to Regular Maternal } \\
\text { Education } \\
(n=48)\end{array}$ & $\begin{array}{c}\text { Assistance to Pilates } \\
\text { Sessions } \\
(n=24)\end{array}$ & $p$-Value \\
\hline Age, mean (SD) & $32.4(5.2)$ & $32.4(5.4)$ & $32.5(4.8)$ & 0.80 \\
\hline Height, mean (SD), m & $1.6(0.0)$ & $1.6(0.1)$ & $1.6(0.1)$ & 0.40 \\
\hline Weight $^{2}$, mean (SD), Kg & $67(10.1)$ & $67.6(10)$ & $65.7(10.3)$ & 0.51 \\
\hline $\mathrm{BMI}^{3}$, mean $(\mathrm{SD}), \mathrm{Kg} / \mathrm{m}^{2}$ & $25.2(3.8)$ & $25.2(3.8)$ & $25.0(4)$ & 0.45 \\
\hline SBP, mean (SD), mmHg & $110.8(10.5)$ & $110.5(11)$ & $111.5(10)$ & 0.40 \\
\hline DBP, mean (SD), mmHg & $67.6(8.5)$ & $67.6(8.6)$ & $67.6(8.6)$ & 0.28 \\
\hline Weeks of Gestation, mean (SD) & $27.3(3.7)$ & $27.3(4.1)$ & $27.3(2.6)$ & 0.69 \\
\hline \multicolumn{5}{|l|}{ Physical Activity, $n(\%)$} \\
\hline Intense & $33(11)$ & $4(8.3)$ & $4(16.7)$ & \multirow{3}{*}{0.42} \\
\hline Moderate & $31(43.1)$ & $23(47.9)$ & $8(33.3)$ & \\
\hline Low & $8(45.8)$ & $21(43.8)$ & $12(50)$ & \\
\hline \multicolumn{5}{|l|}{ Smoking, $n(\%)$} \\
\hline Nonsmoker & $68(94.4)$ & $45(93.8)$ & $23(95.8)$ & \multirow{2}{*}{0.72} \\
\hline Smoker & $4(5.6)$ & $3(6.2)$ & $1(4.2)$ & \\
\hline \multicolumn{5}{|l|}{ Educational level, $n(\%)$} \\
\hline Primary-Secondary. & $26(36.1)$ & $18(37.5)$ & $8(33.3)$ & \multirow{2}{*}{0.59} \\
\hline Superior-Further. & $46(63.9)$ & $30(62.5)$ & $16(66.7)$ & \\
\hline
\end{tabular}

${ }^{1}$ Abbreviations: BMI, body mass index; DBP, diastolic blood pressure; SBP, systolic blood pressure. ${ }^{2,3}$ Weight and BMI before intervention.

\subsection{Onset of Birth, Prevalence of Perineal Trauma and Predictive Variables}

In terms of delivery, it can be noted that most were classified as dystocial $(70.8 \%)$, a circumstance that had no association with the presence or absence of perineal laceration. No differences were found with respect to the use of analgesics (administered in 83.3\% of the cases), the gestation week in which the birth occurred (39.2 (1.4) weeks among those suffering this complication, as opposed to 38.9 (1.5) among those who did not), or whether the birth was induced $(19.4 \%)$ or spontaneous $(80.5 \%)$. Table 3 shows the data concerning the onset and progress of labor with respect to the appearance/non-appearance of laceration, and Table 4 shows the data concerning the weight gain.

Table 3. Characteristics of the sample of pregnant women participants by presence or absence of tearing and crude logistic regression ${ }^{1}$.

\begin{tabular}{|c|c|c|c|c|c|}
\hline Variable & $\begin{array}{l}\text { Presence of Tearing } \\
\qquad(n=30)\end{array}$ & $\begin{array}{l}\text { Absence of Tearing } \\
\qquad(n=42)\end{array}$ & OR Crude & IC $95 \%$ & $p$-Value \\
\hline Age, mean (SD) & $33.4(5.2)$ & $31.7(5.1)$ & 1.07 & $0.97-1.18$ & 0.58 \\
\hline Weight, mean (SD), Kg & $72(11.7)$ & $69.1(10.3)$ & 1.02 & $0.98-1.07$ & 0.58 \\
\hline BMI, mean (SD), $\mathrm{Kg} / \mathrm{m}^{2}$ & $26.8(4.4)$ & $26.1(3.7)$ & 1.04 & $0.93-1.17$ & 0.53 \\
\hline Weight gain during gestation, mean (SD) & $7.3(6.7)$ & $7,05(8,0)$ & 1.01 & $0.94-1.07$ & 0.88 \\
\hline $\mathrm{SBP}$, mean $(\mathrm{SD}), \mathrm{mmHg}$ & $111.9(11.7)$ & $110.7(10.4)$ & 1.01 & $0.97-1.05$ & 0.50 \\
\hline DBP, mean (SD), mmHg & $68.4(7)$ & $67.6(7)$ & 1.02 & $0.95-1.09$ & 0.71 \\
\hline \multicolumn{6}{|l|}{ Physical Activity, $n(\%)$} \\
\hline Low-Moderate & $27(57.8)$ & $37(42.2)$ & 1.22 & $0.27-5.53$ & \multirow{2}{*}{0.59} \\
\hline Intense & $3(37.5)$ & $5(62.5)$ & 1 & 1 & \\
\hline
\end{tabular}


Table 3. Cont.

\begin{tabular}{|c|c|c|c|c|c|}
\hline Variable & $\begin{array}{l}\text { Presence of Tearing } \\
\quad(n=30)\end{array}$ & $\begin{array}{l}\text { Absence of Tearing } \\
\quad(n=42)\end{array}$ & OR Crude & IC $95 \%$ & $p$-Value \\
\hline \multicolumn{6}{|l|}{ Educational level, $n(\%)$} \\
\hline Primary-Secondary. & $9(30)$ & $17(40.5)$ & 0.63 & $0.22-1.7$ & \multirow{2}{*}{0.17} \\
\hline Superior-Further. & $21(70)$ & $25(59.5 .6)$ & 1 & 1 & \\
\hline $\begin{array}{l}\text { Weeks of gestation } \\
\text { at the end intervention, mean (SD) }\end{array}$ & $31.8(4.7)$ & $32.6(4)$ & 0.96 & $0.86-1.07$ & 0.38 \\
\hline \multicolumn{6}{|l|}{ Smoker, $n(\%)$} \\
\hline Nonsmoker & $2(6.7)$ & $2(4.8)$ & 1.43 & $0.2-10.75$ & \multirow{2}{*}{0.89} \\
\hline Smoker & $28(93.3)$ & $40(95.2)$ & 1 & 1 & \\
\hline \multicolumn{6}{|l|}{ Assistance to Pilates, $n(\%)$} \\
\hline Yes & $4(13.3)$ & $20(47.6)$ & 0.17 & $0.05-0.57$ & \multirow{2}{*}{0.007} \\
\hline No & $26(86.7)$ & $22(52.4)$ & 1 & 1 & \\
\hline Weeks of gestation at labor, mean (SD) & $39.2(1.4)$ & $38.9(1.5)$ & 1.18 & $0.82-1.6$ & 0.70 \\
\hline \multicolumn{6}{|l|}{ Type of childbirth, $n(\%)$} \\
\hline Eutocic & $5(16.7)$ & $16(38.1)$ & 0.32 & $0.10-1.02$ & \multirow{2}{*}{0.19} \\
\hline Dystocic & $25(83.3)$ & $26(61.9)$ & 1 & 1 & \\
\hline \multicolumn{6}{|l|}{ Type of labor, $n(\%)$} \\
\hline Induced & $5(16.7)$ & $9(21.4)$ & 0.73 & $0.22-2.46$ & \multirow{2}{*}{0.12} \\
\hline Spontaneous & $25(83.3)$ & $33(78.6)$ & 1 & 1 & \\
\hline \multicolumn{6}{|l|}{ Labor analgesia, $n(\%)$} \\
\hline Yes & $23(76.7)$ & $37(88.1)$ & 0.44 & $0.13-1.57$ & \multirow{2}{*}{0.32} \\
\hline No & $7(23.3)$ & $5(11.9)$ & 1 & 1 & \\
\hline \multicolumn{6}{|l|}{ Episiotomy, $n(\%)$} \\
\hline Yes & $3(10)$ & $28(66.7)$ & 0.06 & $0.01-0.21$ & \multirow{2}{*}{0.006} \\
\hline No & $27(90)$ & $14(33.3)$ & 1 & 1 & \\
\hline Weight of newborns, mean (SD), g & $3302.3(347.5)$ & $3135.6(373.1)$ & 1.00 & $1.000-1.003$ & 0.006 \\
\hline \multicolumn{6}{|c|}{$\begin{array}{l}\text { Pregnant women present at the end of Pilates }(n=24) / \text { Pregnant women present at the end of education program }(n=48) \\
\text { All deliveries were cephalic, and there is no record of posterior cephalic position in any of the records. }\end{array}$} \\
\hline
\end{tabular}

Of the 72 participants, tearing of the vaginal or surrounding tissues occurred in 30 cases, a frequency of $41.7 \%$. The results indicate that this proportion was lower among those women who underwent an episiotomy, with laceration occurring in $9.7 \%$ of the cases, as opposed to $65.9 \%$ in the case of those who did not undergo the procedure (OR, 0.06; 95\% CI, 0.01-0.21). Likewise, participation in the Pilates sessions was demonstrated to be effective, with this complication occurring in the majority of cases (86.7\%) among the women receiving solely the usual antenatal classes (OR, 0.17; 95\% CI, 0.05-0.57) (Table 3) and laceration occurring with a frequency of $54.2 \%$ in this group, in contrast to $16.7 \%$ among those who received the Pilates sessions $(p=0.006)$. 
Table 4. Weight gain during gestation.

\begin{tabular}{|c|c|c|c|c|}
\hline Variable & $\begin{array}{c}\text { Total } \\
(n=72)\end{array}$ & $\begin{array}{l}\text { Assistance to Regular } \\
\text { Maternal Education } \\
(n=48)\end{array}$ & $\begin{array}{l}\text { Assistance to } \\
\text { Pilates Sessions } \\
\quad(n=24)\end{array}$ & $p$-Value \\
\hline \multicolumn{5}{|l|}{ Weight } \\
\hline First trimester ${ }^{1}$ & $63.3(10.1)$ & $63.7(10.4)$ & $62.5(9.7)$ & 0.62 \\
\hline Before the labor & $70.4(10.8)$ & $70.6(10.8)$ & $70.2(11.0)$ & 0.88 \\
\hline \multicolumn{5}{|l|}{ BMI } \\
\hline First trimester ${ }^{1}$ & $23.8(3.7)$ & $23.8(3.7)$ & $23.8(3.7)$ & 0.97 \\
\hline Before the labor & $26.4(4.0)$ & $26.3(4.0)$ & $26.5(4.1)$ & 0.89 \\
\hline $\begin{array}{c}\text { Weight gain } \\
\text { during gestation }\end{array}$ & $7.2(7.4)$ & $6.9(8.2)$ & $7.7(5.8)$ & 0.63 \\
\hline
\end{tabular}

${ }^{1}$ First trimester: $<10$ gestational weeks.

The other variables, namely, age, weight, BMI, blood pressure, level of physical activity, tobacco, weight gain during gestation, and birthweight, showed no association with the occurrence of laceration during labor (Table 3).

Furthermore, when the association of the different variables with this complication was studied using a multivariate binary logistic regression model, it was found that both the performance of an episiotomy and participation in the Pilates sessions have a protective effect against the occurrence of tearing. In addition, the variable education level included in the model indicated that not studied beyond primary or secondary education was associated with a lower probability of injury occurring (Table 5).

Table 5. Binary logistic regression adjusted for age, level of education, episiotomy realization and assistance to Pilates sessions and presence of tearing as outcome variable ${ }^{1}$.

\begin{tabular}{|c|c|c|c|c|}
\hline Variable & Coefficient & OR & IC $95 \%$ & $p$-Value \\
\hline \multicolumn{5}{|l|}{ Educational Level } \\
\hline Primary-Secondary & -1.41 & 0.24 & $0.06-0.98$ & \multirow{2}{*}{0.047} \\
\hline Superior-Further & & 1 & 1 & \\
\hline \multicolumn{5}{|l|}{ Assistance to Pilates } \\
\hline Yes & -1.76 & 0.17 & $0.04-0.78$ & \multirow{2}{*}{0.022} \\
\hline No & & 1 & 1 & \\
\hline \multicolumn{5}{|l|}{ Episiotomy } \\
\hline Yes & -3.2 & 0.04 & $0.09-0.2$ & \multirow{2}{*}{0.001} \\
\hline $\mathrm{No}$ & & 1 & 1 & \\
\hline
\end{tabular}

Log-2 likelihood: 62.94; $\mathrm{R}^{2}$ Cox-Snell: 0.38; $\mathrm{R}^{2}$ Nagelkerke: 0.52; Hosmer-Lemeshow: 0.81, 5 gl $(p=0.98)$.

${ }^{1}$ Abbreviations: IC, confidence interval; OR, odds ratio

\section{Discussion}

This paper aims to evaluate the effectiveness of an intervention model based on the incorporation of an antenatal program of Pilates exercises as a means of preventing perineal trauma during childbirth and so reducing the incidence of female PFD.

The first thing to note is the high frequency of perineal trauma found in our sample $(41.7 \%)$, of particular significance as these figures are used as an indicator of the quality of the healthcare system and the service it provides. Our results contrast with those of a systematic review, which estimates figures of $24 \%$ for second-degree tears and around $1.4 \%$ for third- and fourth-degree tears, both of which are more frequent in primiparae 
deliveries $[27,28]$. Nevertheless, as pointed out, many of the differences in findings between studies are directly linked to differences in healthcare practices at childbirth [29].

An example of this are the findings of D'Souza, in which perineal trauma occurred in more than $85 \%$ of vaginal births, consistent with the figure of $80 \%$ reported by Jansson, which also found first- and second-degree tears more frequent among primiparae, while third- and fourth-degree tears were more frequent among multiparae, at $3.2 \%$ and $4.3 \%$, respectively [28,30].

As can be seen, there is a high degree of disparity among the data, and consequently the results cannot be extrapolated to other populations without taking into account the rate of episiotomies carried out in the health center or the health system in question. In short, the particular healthcare practices put into effect at childbirth are highly significant [31].

In the case of our study, the results show a lower incidence of laceration during childbirth (13.3\% of the total) among those women who attended the Pilates sessions than those who attended solely the usual antenatal classes $(86.7 \%)$, with a prevalence of $16.7 \%$ and $54.2 \%$, respectively. These results support studies of interventions aimed at reducing perineal trauma through PF training programs, such as those described by León-Larios and Dieb. The former reports a figure of $17.6 \%$ for trauma in women who did not follow the program, compared with $6.9 \%$ in the case of those who did. In the latter study, $13.5 \%$ of the pregnant women who followed the PF training suffered trauma, as opposed to $21.5 \%$ of those who did not [6,32].

As can be seen, the results of these studies differ with ours, which may be due in part to the difference in the starting point of the intervention, from weeks 26 to 32 , causing a difference in the women's physical condition in the second and third terms. The duration of the training program might also be influential (between 4 and 8 weeks) since physical activity during pregnancy which promotes continuous strengthening of the PF muscles increases the probability of the perineum remaining intact during childbirth [31]. Another aspect that could account for the variability among the results is the combined use of other techniques for training/strengthening the $\mathrm{PF}$, such as the incorporation of perineal massage [32].

Whatever the case, there is evidence to suggest that Pilates could be a tool for consideration as part of physical preparation programs for childbirth as it focuses muscular work on the abdomen and PF [22,33].

Another finding worthy of note is the association found between a higher level of education and an increase in the risk of trauma. This could be related to an increase in age at childbirth, although the finding needs to be researched in more detail in future studies as no previous study has been found which relates these factors.

On the other hand, the results concur with various previous studies in finding the practice of episiotomy an effective means of preventing tears during childbirth [29,34]. Nevertheless, this issue is controversial, as clinical practice differs greatly from one country to another, ranging from being a systematic practice in all births, as is the case in Argentina and Taiwan, mainly with first-time mothers [35], to being selectively performed in countries such as Sweden and Spain, where it is reserved for those cases in which the benefits outweigh the risks (imminent severe perineal tearing, prolonged second stage of labor, shoulder dystocia, instrumented delivery, and/or non-reassuring fetal heart rate) $[28,29]$. Episiotomies are still commonly practiced in instrumented births, despite there being little research supporting the benefits, as is also the case with spontaneous delivery with respect to a decrease in perineal pain, dyspareunia, urinary incontinence, or prolapse [29].

\section{Limitations}

There are several limitations to this study that oblige us to treat the results with caution. Firstly, the study has a quasi-experimental design, and as such admits the possibility that the participants' willingness to follow the Pilates program could be indicative of a greater concern for the health of the mother and unborn baby during pregnancy and so constitute a selection bias. Whatever the case, it is a type of bias recognized by the literature concerning 
this kind of experimental design [28]. Further, given that the multivariate analysis was able to minimize the possibility of confounding factors, we consider that the study could serve as a model for future experimental-based research. It would be of particular interest to take a larger sample, initiate data collection earlier, and include additional variables that might be associated with the occurrence of perineal trauma (obstetric history, number of previous deliveries, perineal massage prior to delivery, size of the newborn, duration of labor, etc.). Research into the effectiveness and outcomes of the practice of episiotomy, from both the clinical and maternal points of view, would also be desirable.

Finally, another under-researched area is the use of Apps and other digital media to encourage participants to see programs through to the end of their pregnancy. One of the few studies in this area reviews various PF training Apps (in the context of treating urinary incontinence) with a view to improving their adherence strategies [35].

\section{Conclusions}

In summary, although further research is needed into the sustained use of Pilates to develop the PF from the initial stages of pregnancy to childbirth, and its effects in preventing pelvic dysfunctions related to the pregnancy and giving birth, health center managers should promote the training of midwives in the prevention and treatment of pelvic floor injuries during pregnancy, and midwives should consider strategies to enhance adhesion and participation with respect to pelvic floor exercise programs throughout pregnancy by means of Apps and other digital media specifically aimed at this phase.

Author Contributions: Conceptualization, C.F.-R. and J.D.G.-S.; methodology, R.M.-L. and G.M.-R.; formal analysis, C.F.-R., R.M.-L. and G.M.-R.; investigation, C.F.-R. and J.D.G.-S.; resources C.F.-R.; data curation, R.M.-L. and G.M.-R.; writing-original draft preparation, C.F.-R.; writing-review and editing, C.F.-R., J.D.G.-S., R.M.-L. and G.M.-R.; supervision, J.D.G.-S. and G.M.-R. All authors have read and agreed to the published version of the manuscript.

Funding: This research received no external funding.

Institutional Review Board Statement: The study was conducted according to the guidelines of the Declaration of Helsinki, and approved by the Ethics Committee of Servicio Andaluz de Salud (PI021/14, 01/08/2014). Clinical Trial information: ClinicalTrials.gov Identifier: NCT04431102. https: / / clinicaltrials.gov / ct2 / show / NCT04431102?term=CFMP14\&draw=2\&rank=1 accessed on 28 June 2021.

Informed Consent Statement: Informed consent was obtained from all subjects involved in the study.

Acknowledgments: The authors would like to express their gratitude to all those involved in the development of the Pilates sessions, and in particular Marivi, Elena, Ariana, and Celeste, whose disinterested participation, professionality, and dedication made this project possible.

Conflicts of Interest: The authors declare no conflict of interest.

\section{Appendix A}

Table A1. Exercise Schedule of Pilates Method Program.

\begin{tabular}{cccc}
\hline Session $\mathbf{1}$ & Session $\mathbf{2}$ & Session $\mathbf{3}$ & Session $\mathbf{4}$ \\
& & & Squats \\
& & & Squats \\
Squats & Squats & Squated (arms and legs) \\
Pelvis tilt & Pelvis tilt & Push up on knees & The Cat \\
Quadrupled (arms only) & Quadrupled (legs only) & Quadrupled (arms and legs) & The archer \\
The Cat & Arm rotations & Clam & The mermaid \\
The archer & The cat & Side kick & Side leg lifts botton leg \\
The mermaid & The archer & Leg circle & Clam \\
Side leg lifts & The mermaid & Leg lifts & Side kick \\
Clam & Side leg lifts & Pelvic curl & Pelvis tilt \\
Side kick & Clam & Loll-up/roll-down & Leg lifts \\
Leg circle & Side kick & Tiger & Roll-up/roll-down \\
& Leg circle & The mermaid & Leg circle \\
& & & Back support \\
\hline
\end{tabular}


Table A1. Cont.

\begin{tabular}{|c|c|c|c|}
\hline Session 5 & Session 6 & Session 7 & Session 8 \\
\hline $\begin{array}{c}\text { Squats } \\
\text { Quadrupled (arms and legs) } \\
\text { Push up on knees } \\
\text { The cat } \\
\text { Saw } \\
\text { The mermaid } \\
\text { Side leg lifts botton leg } \\
\text { Clam } \\
\text { Side kick } \\
\text { Leg lifts } \\
\text { Roll-up/roll-down } \\
\text { Leg circle } \\
\text { Tiger } \\
\text { Back support }\end{array}$ & $\begin{array}{c}\text { Squats } \\
\text { Working arms with tape } \\
\text { Quadrupled (arms and legs) } \\
\text { Push up on knees } \\
\text { The cat } \\
\text { Saw } \\
\text { Pelvis tilt } \\
\text { The mermaid } \\
\text { Side two legs } \\
\text { Clam } \\
\text { Side kick } \\
\text { Leg lifts } \\
\text { Pelvic curl } \\
\text { Roll-up/roll-down } \\
\text { Leg circle } \\
\text { Back support }\end{array}$ & $\begin{array}{c}\text { Squats } \\
\text { Working arms with tape } \\
\text { Quadrupled (arms and legs) } \\
\text { Push up on knees } \\
\text { The Cat } \\
\text { The archer } \\
\text { Saw } \\
\text { The mermaid } \\
\text { Side two legs } \\
\text { Clam } \\
\text { Side kick } \\
\text { Leg lifts } \\
\text { Pelvic curl } \\
\text { Roll-up/roll-down } \\
\text { Back support } \\
\text { Leg circle } \\
\text { Tiger } \\
\text { Hamstream extension }\end{array}$ & $\begin{array}{c}\text { Squats } \\
\text { Working arms with tape } \\
\text { Quadrupled (arms and legs) } \\
\text { Push up on knees } \\
\text { The Cat } \\
\text { The archer } \\
\text { Saw } \\
\text { The mermaid } \\
\text { Side two legs } \\
\text { Clam } \\
\text { Side kick } \\
\text { Leg lifts } \\
\text { Pelvic curl } \\
\text { Roll-up/roll-down } \\
\text { Leg circle } \\
\text { Hamstream extension } \\
\text { Tiger } \\
\text { Side kick kneeling } \\
\text { Back support }\end{array}$ \\
\hline
\end{tabular}

\section{References}

1. Bozkurt, M.; Yumru, A.E.; Şahin, L. Pelvic floor dysfunction, and effects of pregnancy and mode of delivery on pelvic floor. Taiwan. J. Obstet. Gynecol. 2014, 53, 452-458. [CrossRef] [PubMed]

2. Pierce, H.; Perry, L.; Gallagher, R.; Chiarelli, P. Pelvic floor health: A concept analysis. J. Adv. Nurs. 2015, 71, 991-1004. [CrossRef]

3. Hyakutake, M.T.; Han, V.; Cundiff, G.W.; Baerg, L.; Koenig, N.A.; Lee, T.; Geoffrion, R. Pelvic Floor Health Education. Female Pelvic Med. Reconstr. Surg. 2016, 22, 336-339. [CrossRef]

4. Neels, H.; Wyndaele, J.-J.; Tjalma, W.A.A.; De Wachter, S.; Wyndaele, M.; Vermandel, A. Knowledge of the pelvic floor in nulliparous women. J. Phys. Ther. Sci. 2016, 28, 1524-1533. [CrossRef] [PubMed]

5. Howard, D.; Makhlouf, M. Can pelvic floor dysfunction after vaginal birth be prevented? Int. Urogynecol. J. 2016, 27, 1811-1815. [CrossRef]

6. Leon-Larios, F.; Corrales-Gutierrez, I.; Casado-Mejía, R.; Suarez-Serrano, C. Influence of a pelvic floor training programme to prevent perineal trauma: A quasi-randomised controlled trial. Midwifery 2017, 50, 72-77. [CrossRef] [PubMed]

7. Bose, P.; Haxton, T.; Harding, C.; Lead, M.W. Episiotomy and Perineal Repair Guideline (GL836); Royal Berkshire NHS Foundation Trust: Reading, UK, 2017.

8. Organización Mundial de la Salud. Cuidados en el parto normal: Una guía práctica. Rev. Hosp. Mat. Inf. Ramón Sardá. 1999, 18, 78-80.

9. Escuriet, R.; Pueyo, M.J.; Perez-Botella, M.; Espada, X.; Salgado, I.; Gómez, A.; Biescas, H.; Espiga, I.; White, J.; Fernandez, R.; et al. Cross-sectional study comparing public and private hospitals in Catalonia: Is the practice of routine episiotomy changing? BMC Heal. Serv. Res. 2015, 15, 1-8. [CrossRef] [PubMed]

10. Smith, L.A.; Price, N.; Simonite, V.; Burns, E.E. Incidence of and risk factors for perineal trauma: A prospective observational study. BMC Pregnancy Childbirth 2013, 13, 59. [CrossRef] [PubMed]

11. Oblasser, C.; McCourt, C.; Hanzal, E.; Christie, J. Vibrating vaginal balls to improve pelvic floor muscle performance in women after childbirth: A protocol for a randomised controlled feasibility trial. J. Adv. Nurs. 2016, 72, 900-914. [CrossRef]

12. Davidson, K.; Jacoby, S.; Brown, M.S. Prenatal Perineal Massage: Preventing Lacerations during Delivery. J. Obstet. Gynecol. Neonatal Nurs. 2000, 29, 474-479. [CrossRef] [PubMed]

13. Kyvernitakis, I.; Köhler, C.; Schmidt, S.; Misselwitz, B.; Großmann, J.; Hadji, P.; Kalder, M. Impact of maternal body mass index on the cesarean delivery rate in Germany from 1990 to 2012. J. Périnat. Med. 2015, 43, 449-454. [CrossRef]

14. Helen, L. The Effect of a Pilates Exercise Programme on Perceived Functional Disability and Pain Associated with Non-Specific Chronic Low Back Pain. MOJ Yoga Phys. Ther. 2017, 2. [CrossRef]

15. Guzmán, P.; Díaz, A.M.; Gómez, D.; Guzmán RGuzmán, A. Actuación del fisioterapeuta en el tratamiento integral de la emba-razada. Nure Investig. 2013, 2, 1-8.

16. Shaban, M.M.; Bassiouny, Y.A.; Elzahaby, I.M.; Hassan, A.A. Body mass index and labour outcome in Egyptian women. J. Obstet. Gynaecol. 2013, 34, 248-250. [CrossRef]

17. Navarro, C.L.; Luján, M.I.S. Nuevos sistemas de comunicación del método Pilates en embarazo y puerperio = New communications systems of Pilates Method in pregnancy and postpartum period. Rev. Esp. Comun. Salud. 2017, 8, 20-28. [CrossRef]

18. Almagiá, E. Influencia del estado emocional en la salud física. Terap. Psicol. 2003, 21, 38.

19. Culligan, P.J.; Scherer, J.; Dyer, K.; Priestley, J.; Guingon-White, G.; DelVecchio, D.; Vangeli, M. A randomized clinical trial comparing pelvic floor muscle training to a Pilates exercise program for improving pelvic muscle strength. Int. Urogynecol. J. 2010, 21, 401-408. [CrossRef] 
20. Wells, C.; Kolt, G.; Bialocerkowski, A. Defining Pilates exercise: A systematic review. Complement. Ther. Med. 2012, 20 , $253-262$. [CrossRef]

21. Oktaviani, I. Pilates workouts can reduce pain in pregnant women. Complement. Ther. Clin. Pract. 2018, 31, 349-351. [CrossRef] [PubMed]

22. Dias, N.T.; Ferreira, L.R.; Fernandes, M.G.; Resende, A.P.M.; Pereira-Baldon, V.S. A Pilates exercise program with pelvic floor muscle contraction: Is it effective for pregnant women? A randomized controlled trial. Neurourol. Urodyn. 2018, 37, 379-384. [CrossRef] [PubMed]

23. De Souza, L.M.; Pegorare, A.B.G.D.S.; Christofoletti, G.; Barbosa, S.R.M. Influence of a protocol of Pilates exercises on the contractility of the pelvic floor muscles of non-institutionalized elderly persons. Rev. Bras. Geriatr. Gerontol. 2017, 20, 484-492. [CrossRef]

24. Aceituno, L.; Aguayo, J.; Arribas, L.; Caño, A.; Corona, I.; Martín, J.E.; Mora, M.A.; Ras, J.; Sánchez, T.; Sanz, R. Proceso Asistencial Integrado Embarazo, Parto y Puerperio, 3rd ed.; Consejería de Igualdad, Salud y Políticas Sociales: Sevilla, Spain, 2014; Available online: https://www.juntadeandalucia.es/export/drupaljda/salud_5af1956fa966b_embarazo_parto_puerperio_septiembre_ 2014.pdf (accessed on 17 June 2019).

25. Rodríguez-Díaz, L.; Ruiz-Frutos, C.; Vázquez-Lara, J.M.; Ramírez-Rodrigo, J.; Villaverde-Gutiérrez, C.; Torres-Luque, G. Effectiveness of a physical activity programme based on the Pilates method in pregnancy and labour. Enfermería Clínica 2017, 27, 271-277. [CrossRef] [PubMed]

26. Craig, C.L.; Marshall, A.L.; Sjöström, M.; Bauman, A.E.; Booth, M.L.; Ainsworth, B.E.; Pratt, M.; Ekelund, U.; Yngve, A.; Sallis, J.F.; et al. International Physical Activity Questionnaire: 12-Country Reliability and Validi-ty. Med. Sci. Sports Exerc. 2003, 35, 1381-1395. [CrossRef] [PubMed]

27. Aguiar, M.; Farley, A.; Hope, L.; Amin, A.; Shah, P.; Manaseki-Holland, S. Birth-Related Perineal Trauma in Low- and MiddleIncome Countries: A Systematic Review and Meta-analysis. Matern. Child Health J. 2019, 23, 1048-1070. [CrossRef] [PubMed]

28. D'Souza, J.C.; Monga, A.; Tincello, D.G. Risk factors for perineal trauma in the primiparous population during non-operative vaginal delivery. Int. Urogynecol. J. 2019, 31, 621-625. [CrossRef]

29. Jiang, H.; Qian, X.; Carroli, G.; Garner, P. Selective versus routine use of episiotomy for vaginal birth. Cochrane Database Syst. Rev. 2017, 2, CD000081. [CrossRef]

30. Jansson, M.H.; Nilsson, K.; Franzén, K. Development and validation of a protocol for documentation of obstetric perineal lacerations. Int. Urogynecol. J. 2019, 30, 2069-2076. [CrossRef]

31. Uccella, S.; Manzoni, P.; Marconi, N.; Toscani, C.; Biasoli, S.; Cianci, S.; Franchi, M.; Sorice, P.; Bertoli, F.; Zorzato, P.C.; et al. Impact of Sport Activity and Physical Exercise on Obstetrical and Perineal Outcomes at Delivery: A Prospective Study. Am. J. Perinatol. 2019, 36, S83-S90. [CrossRef]

32. Dieb, A.S.; Shoab, A.Y.; Nabil, H.; Gabr, A.; Abdallah, A.A.; Shaban, M.M.; Attia, A.H. Perineal massage and training reduce perineal trauma in pregnant women older than 35 years: A randomized controlled trial. Int. Urogynecol. J. 2019, 31, 613-619. [CrossRef]

33. Rise, E.; $\mathrm{B} \varnothing, \mathrm{K}$; Nystad, W. Is there any association between abdominal strength training before and during pregnancy and delivery outcome? The Norwegian Mother and Child Cohort Study. Braz. J. Phys. Ther. 2019, 23, 108-115. [CrossRef] [PubMed]

34. Waddington, H.; Aloe, A.M.; Becker, B.J.; Djimeu, E.W.; Hombrados, J.G.; Tugwell, P.; Wells, G.; Reeves, B. Quasi-experimental study designs series—paper 6: Risk of bias assessment. J. Clin. Epidemiol. 2017, 89, 43-52. [CrossRef] [PubMed]

35. Latorre, G.F.S.; De Fraga, R.; Seleme, M.R.; Pt, C.V.M.; Berghmans, B. An ideal e-health system for pelvic floor muscle training adherence: Systematic review. Neurourol. Urodyn. 2019, 38, 63-80. [CrossRef] [PubMed] 